DOI: $10.17516 / 1997-1370-0769$

УДК 316.752

\title{
Features of Values Formation Among Students of Modern Russian Universities
}

\author{
Mikhail Ya. Khrebtova, b and Svetlana V. Berezyuka* \\ ${ }^{a}$ Siberian Federal University \\ Russian Federation, Krasnoyarsk \\ ${ }^{b}$ KrasSMU named after professor V.F. Voino-Yasenetsky Ministry \\ of Health of the Russian Federation \\ Russian Federation, Krasnoyarsk
}

Received 24.03.2021, received in revised form 14.04.2021, accepted 24.05.2021

\begin{abstract}
The relevance of the study is determined by the socio-cultural complexity of the educational space of modern Russian universities. The purpose of the article is to analyze the peculiarities of values formation among students of modern Russian universities. To achieve this goal, it is also necessary to test one of the possible methods for measuring the value attitudes of Russian university students based on a questionnaire using the author's list of questions.

The methods of field work in the universities of the regions of the Siberian Federal District with the help of on-line technologies: questionnaires and statistical processing of the data obtained were used. The method of critical analysis of modern pedagogical concepts was applied. Licensed IBM SPSS software was used to identify statistical patterns and correlations of field study results.

504 questionnaires of undergraduate and graduate students of the universities of the Krasnoyarsk Krai, the Republic of Tuva, the Tomsk Oblast, the Irkutsk Oblast, the Republic of Khakassia, the Novosibirsk Oblast, the Omsk Oblast, and the Altai Krai were surveyed and processed. The features of values formation related to the value of communications have been recorded: 1) contrary to the stereotypes about the prevalence of the values of virtual communication in certain age categories of students, only $2.7 \%$ prefer exclusively virtual communication. The share of the respondents who prefer direct communication with people is quite high $-42.6 \%$. In the age group from 17 to 24 years, this share is slightly less and amounts $40.7 \%$. Exclusively virtual communications in this age category is chosen by $2.1 \%$ of the respondents; 2 ) the symbolic mediators of the value environment of students are changing: for $78.6 \%$ of students shopping and entertainment centers are preferred places for spending their free time, in the age group from 17 to 24 years this share rises to $80.4 \%$; at the same time, libraries reduce their influence on the value perceptions of students: only $16.5 \%$ of the respondents visit libraries in their free time, in the age group from 17 to 24 years this share is slightly higher and amounts $16.6 \%$; among social networks, the social network Vkontakte has
\end{abstract}

\footnotetext{
(C) Siberian Federal University. All rights reserved

* Corresponding author E-mail address: khrebtov.m@mail.ru ORCID: 0000-0003-2689-7058 (Khrebtov)
} 
the highest value of a symbolic mediator for Russian students: $94.2 \%$ of the respondents of all age categories use this network for communications; for the age group from 17 to 24 years this share is even higher and amounts $96.3 \%$; 3 ) the technological base for the formation of students' value perceptions is changing, Internet technologies are used both for entertainment and for reading books by $59.5 \%$ of students, in the age category from 17 to 24 years this share significantly prevails and amounts $64 \%$.

The peculiarities of the formation of students' value ideas must be taken into account when developing evaluative tools for the universal competence «diversity of cultures», among other things including the research component in the corresponding evaluation procedures.

Keywords: values, multicultural educational environment, universal competences, cultural diversity, value transformations, symbolic mediators.

The reported study was funded by RFBR, project number 19-311-90017.

Research area: theory and history of culture (cultural studies).

Citation: Khrebtov, M. Ya., Berezyuk, S.V. (2021). Features of values formation among students of modern Russian universities. J. Sib. Fed. Univ. Humanit. Soc. Sci., 14(6), 897-917. DOI: 10.17516/19971370-0769.

\title{
Особенности формирования ценностей у студентов современных российских университетов
}

\author{
М.Я. Хребтов \\ ${ }^{a}$ Сибирский федеральный университет \\ Российская Федераџия, Красноярск \\ ${ }^{\sigma}$ КрасГМУ им. профессора В.Ф. Войно-Ясенеикого МЗ РФ \\ Российская Федерачия, Красноярск
}

\begin{abstract}
Аннотация. Актуальность исследования определяется социально-культурной сложностью образовательного пространства современных российских университетов. Цель статьи - провести анализ особенностей формирования ценностей студентов современных российских университетов. Для реализации этой цели необходимо также выполнить апробацию одной из возможных методик измерения ценностных установок студентов российских университетов, основанную на анкетировании с применением авторского опросника.

Использованы методы полевой работы в университетах регионов Сибирского федерального округа с помощью on-line-технологий: анкетирования и статистической обработки полученных данных. Был применен метод критического анализа современных педагогических концепций. Для выявления статистических закономерностей и корреляций результатов полевого исследования использовали лицензионное программное обеспечение IBM SPSS.

Проведено анкетирование и обработано 504 анкеты студентов бакалавриата и магистратуры университетов Красноярского края, Республики Тыва, Томской


области, Иркутской области, Республики Хакасия, Новосибирской области, Омской области, Алтайского края. Зафиксированы особенности формирования ценностей, связанные с ценностью коммуникаций: 1) вопреки стереотипам о преобладании ценностей виртуального общения в определенных возрастных категориях студентов всего $2,7 \%$ предпочитают исключительно виртуальное общение. Достаточно высока доля респондентов, которые предпочитают непосредственное общение с людьми - 42,6\%. В возрастной категории от 17 до 24 лет эта доля чуть меньше и составляет $40,7 \%$. Исключительно виртуальные коммуникации в этой возрастной категории выбирают $2,1 \%$ респондентов; 2) изменяются символические медиаторы ценностной среды студентов: для 78,6 \% студентов преимущественным местом для их свободного времяпровождения являются торгово-развлекательные центры, в возрастной категории от 17 до 24 лет эта доля возрастает до 80,4 \%; одновременно библиотеки снижают свое влияние на ценностные представления студентов: лишь 16,5 \% респондентов посещают библиотеки в свободное время, в возрастной категории от 17 до 24 лет эта доля незначительно выше и составляет $16,6 \%$; среди социальных сетей для российских студентов значение символического медиатора наиболее высоко у социальной сети «Вконтакте»: 94,2 \% респондентов всех возрастных категорий используют данную сеть для своих коммуникаций; в возрастной категории от 17 до 24 лет эта доля еще больше и составляет 96,3\%; 3) изменяется технологическая база для формирования ценностных представлений студентов, интернет-технологии используют как для развлечения, так и для чтения книг 59,5 \% студентов, в возрастной категории от 17 до 24 лет эта доля существенно преобладает и составляет $64 \%$.

Особенности формирования ценностных представлений студентов необходимо учитывать при разработке оценочных средств для универсальной компетенции «многообразие культур», в том числе включить исследовательскую компоненту в соответствующие оценочные процедуры.

Ключевые слова: ценности, поликультурная образовательная среда, универсальные компетенции, многообразие культур, ценностные трансформации, символические медиаторы.

Исследование выполнено при финансовой поддержке РФФИ в рамках научного проекта № 19-311-90017.

Научная специальность: 24.00.01 - теория и история культуры (культурология).

\section{Введение}

Актуальность исследования связана с рядом факторов, определяющих образовательное пространство современных российских университетов, среди которых можно выделить социальнокультурную сложность студенчества и преподавателей, различие условий формирования мировоззрения у тех или иных социально-демографических групп, трансформационные процессы, характерные для социально-экономических и культурных сообществ как во всем мире, так и в совре- менной России, формирование цивилизационных основ, характерных для новых технологических укладов, активные интеллектуальные и публичные дискуссии, связанные с поиском мировоззренческих позиций, адекватных современным вызовам, и ряд других. Ценностные представления студентов - исходная позиция для формирования ряда универсальных компетенций, обозначенных в утвержденных федеральных государственных стандартах высшего образования. Понятно, что эффективность формирования этих компетенций, 
связанных с личностными изменениями и с активным влиянием образовательных практик современного университета на эти личностные изменения, во многом определяется пониманием исходных ценностных установок, с которыми студенты приходят в университеты и включаются в образовательный процесс. Как правило, университеты самостоятельно формируют содержание образовательных программ и закрепляют за различными учебными дисциплинами задачу формирования универсальных компетенций. В настоящее время Российское государство добавляет к этим устоявшимся практикам задачу успешной реализации молодежной политики по отношению к студентам, составляющим зачастую ядро молодежных социальных групп того или иного региона. Российские университеты разрабатывают концепции реализации своей молодежной политики, создаются новые структуры и вводятся новые должности для ответственных за эффективную молодежную политику как в системе менеджмента университета в целом, так и в отдельных структурных подразделениях - институтах, факультетах, отделениях.

С учетом динамики ценностных представлений всех без исключения социальных групп, составляющих современное российское общество, развиваются различные педагогические практики, ориентированные на понимание значительных отличий мировоззренческих установок преподавателей и студентов. В структуру этих практик входят обязательные исследовательские компоненты, предполагающие активную позицию педагогов университетов, которые корректируют свои технологии в зависимости от обнаруженных ими особенностей мировоззрения студентов, изучающих их дисциплины. Особое значение предварительная исследовательская работа по выяснению ценностных представлений студентов имеет для преподавателей учебных дисциплин, изначально несущих те или иные мировоззренческие смыслы, значения, принципы. Речь идет об истории, философии, культурологии, политологии и ряде других социально-гуманитарных дисциплин. Здесь, на наш взгляд, предварительное аксиологическое исследование студентов и мониторинг динамики ценностных установок были бы наиболее полезны и эффективны для достижения образовательных целей и задач.

Одно из наиболее цитируемых исследований по проблеме влияния персональных ценностей студентов на результаты их обучения было сделано американскими учеными П.Р. Пинтричем и Е.В. Де Гроотом в начале 1990-х гг. Авторы утверждали, что самое большое влияние на эффективность образовательных результатов имеют степень саморегуляции, степень самоэффективности, уровень тревожности и выбор когнитивных стратегий при выполнении заданий. При этом собственные ценности студентов сами по себе не влияют на их успешность, но оказывают воздействие на степень саморегуляции и выбор когнитивных стратегий (Balakrishnan et al., 2021). С данного исследования начинается академическая традиция изучать ценности обучающихся в контексте анализа мотивационной ориентации и стремления студентов к достижению высоких результатов. Не менее влиятельное исследование этого же периода, сделанное канадскими учеными Э. Л. Диси и соавторами, показывает, что поощрение у обучающихся ценностей образования, личностного роста, уверенности в своих способностях и качествах имеют беспрецедентно высокое влияние на процессы адаптации к сложностям образовательного процесса и достижение высоких качественных результатов (Schwartz, Bilsky, 1990) Значимость этого исследования связана также с акцентированием роли социально-культурного контекста конкретного образовательного пространства.

Концептуальной основой для развития педагогических практик, оказывающих активное воздействие на мотивацию студентов, выступает теория самоопределения Э.Л. Диси и Р.М. Райана, которые утверждают, что три основных психологических потребности - в автономности, компетенции и взаимодействии - при их удовлетворении усиливают мотивированность, 
саморегуляцию и благополучие в сфере образования и не только. Эти психологические потребности людей важны для сфер здравоохранения, профессиональной деятельности, спорта, религии, психологической терапии (Broadbent, 2017). Наоборот, естественные процессы самомотивации и здорового психологического развития начинают тормозиться, если данные психологические потребности не удовлетворяются.

В современной педагогической науке обсуждаются актуальные технологии повышения мотивации студентов к эффективному обучению и влияние на ценностные представления студентов через создание иммерсивной образовательной среды. Большое внимание уделяется критическому анализу новых образовательных инструментов, связанных с введением иммерсивной виртуальной реальности в процесс обучения. Больше присутствия, но меньше обучения при увеличении общей когнитивной нагрузки при применении иммерсивной виртуальной реальности в образовательных практиках фиксируют датские ученые Г. Макрански и соавторы. Мотивация к обучению повышается, но эффективность образовательных результатов снижается, делают вывод исследователи (Covarrubias, 2021). Такие же выводы о повышении мотивации студентов к обучению, но снижению эффективности обучения при использовании иммерсивной виртуальной реальности, были сделаны американскими учеными Дж. Паронгом и Р. Майером (Deci et al., 1991). Очевидно, что новые технологии, ориентированные на актуальные интересы современных студентов, на применение технологии погружения в виртуальную реальность для целей образования, требуют дальнейших исследований, в том числе медико-психологических.

Влияние культурных ценностей студентов на их мотивацию к успешному обучению в новых технологических средах исследуют американские ученые А. Тархини и соавторы, которые показывают, что культурное происхождение студентов в ориентации ценности полезности, удобства и качества будущей профессии влияют на их выбор электронных средств образования. И даже ценность качества будущей трудовой деятельности не смогла смягчить индивидуальную сдержанность при выборе электронных средств студентами, имеющими культурное происхождение, связанное с традиционными установками (Donald, Baruch, Ashleigh, 2019).

Степень воздействия на мотивационные и ценностные установки студентов образовательных технологий смешанного или исключительно электронного образования анализировал австралийский ученый Дж. Бродбент, который подчеркивает значимость ценности саморегуляции и самоуправления временем для студентов, но при этом он не находит различий в достижении качественных учебных результатов при выборе студентами или смешанного, или сугубо электронного образования (Earley, Ang, 2003).

Такой технологический акцент современной педагогической науки не означает ее отказа от анализа мировоззренческих установок студентов. Другое дело, что здесь также намечается переход от фиксации статичных представлений к анализу динамики содержания этих представлений, а также к кросс-культурным исследованиям, которые показывают конкретную культурную обусловленность результативности образовательного процесса студентов современных университетов. В зоне пристального внимания ученых-педагогов находятся поликультурные образовательные среды, характерные для современных американских и ряда европейских университетов.

Наиболее влиятельной концепцией культурных ценностей, позволяющей делать соответствующие педагогические измерения, в том числе, кросс-культурные измерения в студенческих средах, признана теория основных человеческих ценностей американского исследователя Ш. Шварца, который в настоящее время является президентом Международной ассоциации кросс-культурной психологии. Впервые сама теория и результаты применения этой теории к кросс-культурным исследованиям в 20 странах были опубликованы в нача- 
ле 1990-х гг., в том числе важное значение имела научная статья Ш. Шварца 1992 г. «Универсалии в содержании и структуре ценностей: теория и эмпирические тесты в 20 странах» (Hu, Dai, 2021), на основе которой в течение 30 лет проводятся соответствующие исследования в различных социально-культурных средах. Так, в работе Ш. Шварца и соавторов 2001 г. анализируется культурное своеобразие ценностных установок студентов Уганды и Италии, а также делается вывод о валидности теории основных человеческих ценностей для психолого-педагогических кросс-культурных исследований ( $\mathrm{Hu}, \mathrm{Gu}$, Liu, Huang, 2003). В 2019 г. Ш. Шварц и его коллеги изучали динамику ценностей молодых европейцев в ситуации серьезного экономического кризиса (Katz et al., 2017), где показали определенный ценностный парадокс, фиксирующий усиление традиционных ценностей в странах с современными модернизационными экономическими процессами и снижение ценностей достижения личного успеха в странах, потерпевших большой экономический ущерб.

Действительно, экономические кризисы, характерные для современных стран, по-новому ставят проблему ценностных культурных представлений студентов и выпускников современных университетов. Прямое влияние культурных идентичностей на успешность выпускников университетов на рынках труда рассматривает британский ученый М. Томлинсон, который предлагает новую модель трудоустройства выпускника, предполагающую создание в ходе образования ряда форм человеческого (личностного) капитала, в том числе социально-культурного (Louis, Murphy, 2017). Эта позиция близка к моделям развития универсальных компетенций, которые внедряются сегодня в российских университетах.

Этнокультурные аспекты ценностей актуальная тема современных научных исследований. Как правило, для анализа привлекаются данные полевых исследований, включенные наблюдения, проводимые в местах компактного проживания соот- ветствующих этнокультурных групп. Так, Н. П. Копцева и В.И. Кирко на протяжении ряда лет изучают динамику культурных ценностей, характерных для коренных малочисленных народов Красноярского края (Koptseva, Kirko, 2014a, Koptseva, Kirko, 2014b), стандарты полевых исследований для анализа этнокультурных ценностей разрабатывают Н. П. Копцева и К. В. Резникова (Koptseva, Reznikova, 2015).

Стремительная динамика социальных взаимодействий и появление технологических возможностей для реализации новой деловой этики в университетах приводят к появлению достаточно дискуссионных концепций образовательных действий, в том числе к созданию концепции «студента как партнера». Необходимость осторожного отношения к этой концепции и в том числе тщательного учета культурноценностных представлений обучающихся об этике заботы и лиминальности студентов обосновывается в исследовании австралийских ученых К. Е. Мэтьюза и соавторов, выполненном на полевом материале, полученном в 11 австралийских университетах (Makransky et al., 2019).

Новый вид педагогических исследований возникает на основе т. н. позитивной психологии. Так, в научной статье американских ученых К. Луиса и Дж. Марфи рассматривается проблема воздействия лидерских качеств руководителя образовательного учреждения и его культурноценностных представлений на эффективность обучения, особенно для студентов из семей с низкими экономическими показателями. Культивирование ценностей заботы и доверия со стороны руководителей по отношению к педагогам и студентам определяется как существенный фактор повышения эффективности образования в данном учебном заведении. Это эмпирическое исследование имеет ряд перспектив, и дальнейший анализ т. н. позитивного лидерства по отношению к университетам еще впереди (Matthews et al., 2018).

Современные университеты берут на себя социальную ответственность за трудоустройство своих выпускников, 
что предопределяет еще одну значимую тенденцию в педагогике высшего образования, опирающуюся на изучение связи и зависимости качества профессиональной и карьерной ориентации студентов в годы их обучения с успешностью этих студентов на современных рынках труда. Совокупность культурно-ценностных установок как культурный капитал выпускника и влияние культурного капитала на карьерную успешность студентов анализируют британские ученые М. Дональд и соавторы на материале эмпирического исследования 387 студентов и выпускников британских университетов. Выводы исследователей позволяют подчеркнуть успешность такой специализированной профориентационной подготовки и освоить ряд рекомендаций, которые делаются для ее совершенствования (Moghavvemi et al., 2017).

С начала 2000-х гг. появляются и закрепляются в педагогических исследованиях термины «культурный интеллект» и «культурный коэффициент», английскими аналогами которых являются «cultural intelligence» и «cultural quotient» соответственно (Person et al., 2021). В федеральных государственных образовательных стандартах эти понятия примерно совпадают с универсальной компетенцией «многообразие культур», под которой подразумевается способность работать в разных культурных средах и эффективно взаимодействовать с людьми и группами, имеющими различные культурные установки. Одновременно в связи с лавинообразным ростом влияния социальных сетей появляются и увеличиваются с каждым годом исследования социальных медиа в педагогическом контексте. Эти две актуальные тенденции педагогической науки были объединены в научной статье С. Ху и соавторов, где были проанализированы возможности социальных сетей влиять на культурный интеллект и способность к межкультурной коммуникации студентов китайских университетских колледжей (Parong, Mayer, 2018).

Не только экономический, но и экологический кризис определяет актуальные тенденции педагогических исследований культурных ценностей студентов. Израильские и американские ученые Т. Кац-Герро и соавторы исследуют культурную специфику ценности биосферного единства, универсализма и доброжелательности представителей Германии, Израиля, Южной Кореи и Индии и раскрывают значительную специфику каждого социально-культурного сообщества, представленного этими странами (Pintrich, Groot, 1990). Соответственно, образовательные модели формирования экологических ценностей у студентов также должны учитывать специфику их культурного происхождения.

Социально-культурная специфика свойственна не только различным национально-культурным группам, но и современным урбанистическим культурным сообществам. Особые образовательные программы и технологии для воспитания лидеров городских молодежных сообществ, имеющих различное культурное происхождение, обсуждаются и предлагаются американскими исследователями Д.Р. Персоном и соавторами, которые также акцентируют значимость ценности доброжелательности по отношению к обучающимся со стороны образовательных организаций, указывают на возрастающую сложность городских систем образования и проблемные зоны, связанные с различным уровнем экономического благосостояния семей, дети которых претендуют на роль лидеров городских молодежных сообществ (Ryan, Deci, 2000).

Изменение социально-культурного статуса современных студентов американских городских университетов, преобладание в них представителей латиноамериканских мигрантов первого поколения и соответствующее изменение культурноценностных ориентаций студенчества обсуждает американский ученый Р. Коваррубиас. Он фиксирует противоречие между традиционной ориентацией классических университетов на ценности индивидуализма и культурное происхождение студентов из семей высшего и среднего экономических классов с прямо противоположными ценностями семейного коллективизма и происхождением из семей низших 
экономических классов студентов, которые сегодня пришли в эти университеты. Автор справедливо утверждает, что должны измениться инвестиционные стратегии правительства и благотворителей: инвестировать в студентов латиноамериканского происхождения - это означает инвестировать в их семьи. На основе данного исследования предлагаются конкретные механизмы изменения инвестиционных стратегий для студентов современных американских университетов (Schwartz, 1992). Представляется, что подобные проблемы можно встретить и в российских университетах, куда приходят учиться мигранты первого поколения из стран постсоветского пространства. Исследования в этой области актуальны для современной российской педагогики.

Большой объем педагогических исследований культурных ценностей связан с религиозностью и иррелигиозностью студентов, что важно, например, для стран, где преобладает исламская религия, в том числе для Малайзии, которая сегодня запускает ряд модернизационных процессов в высшем образовании. Международный коллектив ученых из Малайзии, Саудовской Аравии и Японии - Б. Балакришнан и соавторы - выявил значительное влияние культурных и религиозных ценностей на инженерную этику студентов инженерных специальностей в Малайзии. Ученые полагают, что эту религиозно-культурную специфику необходимо учитывать в действующих моделях высшего образования и продолжать изучать ее воздействие на выбор конкретных этических действий, которые совершают будущие инженеры (Schwartz et al., 2001).

Новый ракурс проблеме межкультурных коммуникаций в современных университетах задают китайские исследователи Я. Ху и К. Дай, предметом анализа которых является изменение культурной идентичности студентов китайских университетов из числа китайских иммигрантов, вернувшихся для получения высшего образования в Китай как свою историческую родину. В связи с этим поднимаются фундамен- тальные проблемы управления культурной и исторической памятью студентов, поощрения международных связей и академических обменов, преодоление языковых и культурных барьеров в едином университетском пространстве (Sortheix et al., 2019).

Актуальные тенденции исследования культурных ценностей студентов, представленные в современной педагогике, достаточно разнообразны. Можно выделить два основных вектора этих исследований. Первый связан с влиянием культурных ценностей, установок, норм на усиление мотивации студентов к повышению эффективности своего образования. В этом же русле развивается изучение культурной специфики выбора конкретных методик для использования современных образовательных инструментов, прежде всего виртуальной реальности, электронного образования, когнитивных стратегий учащихся. Второй вектор имеет примерно тридцатилетнюю традицию кросс-культурных исследований в области образования и связан с разработкой методик замеров культурного интеллекта или культурного коэффициента, с одной стороны, с исследованиями динамики культурных установок студентов в конкретных университетах и сообществах - с другой.

Представляется, что формирование универсальной компетенции федеральных государственных образовательных стандартов высшего образования «многообразие культур» ориентировано на второй вектор, связанный с формированием культурного интеллекта и успешности межкультурных коммуникаций в современном мире, в профессиональной сфере и повседневной деятельности. Но нельзя недооценивать и целенаправленное формирование мотивации к достижению высоких образовательных результатов с помощью воздействия на конкретные субъективные ценностные установки студентов. И в том и в другом случае необходимость выявления исходных культурно-ценностных представлений студентов обоснованна. Для повышения качества образования в современных российских университетах в образовательную модель должна быть 
включена перманентная исследовательская компонента, связанная с выявлением и анализом культурных ценностей студентов и динамики этих ценностей. Более того, одним из оценочных средств для проверки достижения ряда универсальных компетенций могут выступить результаты замеров культурно-ценностной динамики студентов, что предполагает также тщательное и достоверное обоснование выбора методик для проведения данных замеров.

Цель данного исследования - провести анализ особенностей формирования ценностей студентов современных российских университетов. Для реализации этой цели необходимо также выполнить апробацию одной из возможных методик измерения ценностных установок студентов российских университетов, основанную на анкетировании с использованием авторского вопросника. Апробация была проведена на полевом материале, полученном в регионах Сибирского федерального округа с помощью организации on-line-тестирования в системе Google-анкетирования. Выбор регионов Сибирского федерального округа репрезентативен для современного российского поликультурного образовательного пространства, поскольку здесь расположены университеты республик Хакасия, Бурятия, Тыва с широкой представленностью в них различных этнокультурных групп, в том числе принадлежащих к коренным народам Сибири. При этом для университетов Новосибирской, Иркутской, Омской областей, Красноярского края и других регионов также характерно многообразие культурных установок студентов и преподавателей, в том числе за счет достаточно большого количества обучающихся, принадлежащих к мигрантам первого и второго поколения из стран постсоветского пространства.

\section{Материалы и методы}

Материалами исследования выступили результаты полевого исследования, полученные с помощью анкетирования молодежи и студентов в возрасте от 17 до 40 лет. Данные были собраны с помощью автор- ской Google-анкеты и организованного on-line-анкетирования для ряда регионов Сибирского федерального округа, в том числе Красноярского края, Республики Тыва, Томской области, Иркутской области, Республики Хакасия, Новосибирской области, Омской области, Алтайского края. Период проведения полевого исследования - 2019-2020 гг. Общее количество респондентов составило 504 человека, в том числе 246 мужчин и 258 женщин. По роду занятий респонденты - это студенты различных направлений бакалавриата и магистратуры, что объясняет их широкий возрастной диапазон. Студенты в возрасте от 22 до 40 лет - это, как правило, обучающиеся по образовательным программам магистратуры, студенты в возрасте от 17 до 21 года - обучающиеся по образовательным программам бакалавриата.

В основу анкеты лег вопросник, разработанный авторами данной статьи. Для разделов и формулировок вопросов, связанных с выяснением ценностных установок и представлений студентов современных российских университетов, были выбраны подходы, связанные с классификацией мотиваций людей Ш. Шварца (Stvilia, Gibradze, 2017) и теорией динамических отношений между ведущими типами человеческих мотиваций У. Билски (Tarhini et al., 2017). Вопросы анкеты были составлены таким образом, чтобы отразить содержание следующих базовых человеческих ценностей: ценности общения и взаимодействия; ценности семьи, брака, детей; ценности здоровья, здорового образа жизни, спорта и физической культуры; ценности отдыха и развлечений; ценности интеллектуального времяпровождения; ценность использования современных информационных технологий; ценность патриотизма, любви к малой и большой родине; материальные ценности.

В связи с большим объемом полученных данных необходимо в данном исследовании ограничить материалы ключевыми темами, связанными с коммуникативными практиками и с использованием современных информационных технологий и со- 
циальных медиа, что является актуальной тенденцией для студентов всего мира и для студентов современных российских университетов в том числе.

Ответы на вопросы предполагали выбор одного из вариантов ответов, представленных в анкете, также была возможность выбрать позиции «затрудняюсь ответить» и «нет ответа». Для обработки массива данных применяли лицензионное программное обеспечение IBM SPSS, что позволило выявить значимые корреляции, а также представить обработанные данные в виде таблиц, диграмм, графиков.

Полученные данные были использованы для теоретической интерпретации и научного моделирования, что позволило выявить определенную специфику формирования ценностей у студентов современных российских университетов, расположенных в ряде регионов Сибирского федерального округа, уточнить существующие научные модели ценностных представлений российского студенчества, а также провести апробацию авторского вопросника.

\section{Результаты исследования}

Рассмотрим содержание ответов на вопросы, связанные с коммуникативными практиками и их особенностями. В табл. 1 показано распределение по возрастным

Таблица 1. Возрастное распределение ответов респондентов на вопрос «Общительный ли Вы человек?»

Table 1. Age distribution of respondents' answers to the question «Are you a sociable person?»

\begin{tabular}{|c|c|c|c|c|c|}
\hline $\begin{array}{c}\text { Возраст } \\
\text { респондентов }\end{array}$ & $\begin{array}{c}\text { Да, } \\
\text { я общительный }\end{array}$ & $\begin{array}{c}\text { Мне сложно быть } \\
\text { общительным, } \\
\text { но я работаю над этим }\end{array}$ & $\begin{array}{l}\text { Скорее всего } \\
\text { общительный }\end{array}$ & $\begin{array}{c}\text { Мне сложно } \\
\text { коммуницировать } \\
\text { с людьми } \\
\end{array}$ & Всего \\
\hline 1 & 2 & 3 & 4 & 5 & 6 \\
\hline 17 & 2 & 2 & 5 & 0 & 9 \\
\hline 18 & 31 & 11 & 22 & 2 & 66 \\
\hline 19 & 29 & 14 & 21 & 1 & 65 \\
\hline 20 & 40 & 25 & 27 & 1 & 93 \\
\hline 21 & 12 & 2 & 13 & 1 & 28 \\
\hline 22 & 7 & 2 & 6 & 0 & 15 \\
\hline 23 & 12 & 10 & 6 & 1 & 29 \\
\hline 24 & 13 & 5 & 8 & 0 & 26 \\
\hline 25 & 6 & 5 & 2 & 1 & 14 \\
\hline 26 & 5 & 1 & 2 & 0 & 8 \\
\hline 27 & 9 & 3 & 5 & 0 & 17 \\
\hline 28 & 9 & 2 & 5 & 2 & 18 \\
\hline 29 & 3 & 1 & 2 & 0 & 6 \\
\hline 30 & 16 & 5 & 19 & 0 & 40 \\
\hline 31 & 11 & 9 & 13 & 2 & 35 \\
\hline 32 & 5 & 1 & 0 & 1 & 7 \\
\hline 33 & 1 & 0 & 0 & 0 & 1 \\
\hline 34 & 1 & 0 & 0 & 0 & 1 \\
\hline 35 & 7 & 0 & 2 & 1 & 10 \\
\hline 36 & 2 & 0 & 0 & 0 & 2 \\
\hline 37 & 2 & 0 & 0 & 0 & 2 \\
\hline
\end{tabular}


Продолжение табл. 1

Continued Table 1

\begin{tabular}{|c|c|c|c|c|c|}
\hline 1 & 2 & 3 & 4 & 5 & 6 \\
\hline 38 & 1 & 0 & 2 & 0 & 3 \\
\hline 39 & 4 & 0 & 1 & 0 & 5 \\
\hline 40 & 3 & 0 & 1 & 0 & 4 \\
\hline Всего & 231 & 98 & 162 & 13 & 504 \\
\hline
\end{tabular}

группам ответа на вопрос анкеты «Общительный ли Вы человек?».

На основании данных этой таблицы можно увидеть, что подавляющее большинство респондентов всех возрастных групп - 97,4 \% - либо относят себя к категории очень общительных людей, либо стремятся такими быть. По возрастным группам лидируют респонденты в возрасте от 17 до 24 лет, здесь общительными считают себя или стремятся к этому 98,2 \% респондентов.

В табл. 2 представлено возрастное распределение ответов респондентов на вопрос «Предпочитаете ли Вы непосредственное общение с людьми или виртуальное?».

Несмотря на стереотипное мнение о том, что люди в возрастной категории 17+ предпочитают исключительно виртуальное общение, данные в табл. 2 показывают, что таковых среди наших респондентов оказалось крайне незначительное количество - всего 2,7 \%. Достаточно высока доля респондентов, которые предпочитают непосредственное общение с людьми - 42,6 \%. В возрастной категории от 17 до 24 лет эта доля чуть меньше и составляет 40,7 \%. Исключительно виртуальные коммуникации в этой возрастной категории выбирают $2,1 \%$ респондентов.

В табл. 3 по возрастным категориям обобщены данные, связанные с использованием интернета для развлечений в свободное времяпровождение наших респондентов.

Во всех возрастных категориях преобладает положительный ответ - 59,5 \%. В возрастной категории от 17 до 24 лет положительный ответ существенно преобладает и составляет $64 \%$.
Важное значение для современных коммуникаций российских студентов играют социальные сети. Предварительный анализ показал, что наиболее распространенной может быть социальная сеть «Вконтакте». В табл. 4 представлены возрастные градации ответов респондентов на вопрос «Используете ли Вы социальную сеть «Вконтакте»?»

Полученные данные подтвердили предварительное суждение о том, что социальная сеть «ВКонтакте» очень популярна в современной студенческой среде. 94,2 \% респондентов всех возрастных категорий используют данную сеть для своих коммуникаций. В возрастной категории от 17 до 24 лет эта доля еще больше и составляет $96,3 \%$.

Для сравнения в табл. 5 приведены данные, связанные с вопросом об использовании социальной сети Facebook.

Можно увидеть разительное отличие от данных табл. 4. Лишь 6,2 \% респондентов всех возрастных категорий для коммуникаций используют сеть Facebook. В возрастном диапазоне от 17 до 24 лет эта доля составляет всего около $4 \%$.

Для исследования важны различные факторы, влияющие на ценностные представления студентов. Так, можно выявить основные медиаторы, которые могут оказывать такое влияние, или указать на снижение влияния некоторых традиционных культурных институций, участвующих в формировании ценностей в предыдущие исторические периоды. Например, можно сравнить значение торгово-развлекательных центров и библиотек в жизни наших респондентов (табл. 6). 
Таблица 2. Возрастное распределение ответов респондентов на вопрос «Предпочитаете ли Вы непосредственное общение с людьми или виртуальное?»

Table 2. Age distribution of respondents' answers to the question «Do you prefer direct communication with people or virtual?»

\begin{tabular}{|c|c|c|c|c|c|}
\hline $\begin{array}{c}\text { Возраст } \\
\text { респондентов }\end{array}$ & $\begin{array}{c}\text { Мне нравится } \\
\text { общаться } \\
\text { непосредственно, } \\
\text { не on-line }\end{array}$ & $\begin{array}{c}\text { Мне } \\
\text { безразлично }\end{array}$ & $\begin{array}{c}\text { Мне нравится общаться } \\
\text { с людьми непосредственно, } \\
\text { но я спокойно } \\
\text { общаюсь и on-line }\end{array}$ & $\begin{array}{l}\text { Мне комфортно } \\
\text { общаться on-line }\end{array}$ & Всего \\
\hline 17 & 4 & 2 & 3 & 0 & 9 \\
\hline 18 & 30 & 16 & 19 & 1 & 66 \\
\hline 19 & 34 & 10 & 20 & 1 & 65 \\
\hline 20 & 31 & 14 & 42 & 6 & 93 \\
\hline 21 & 8 & 6 & 14 & 0 & 28 \\
\hline 22 & 5 & 1 & 8 & 1 & 15 \\
\hline 23 & 12 & 5 & 12 & 0 & 29 \\
\hline 24 & 11 & 3 & 12 & 0 & 26 \\
\hline 25 & 7 & 3 & 4 & 0 & 14 \\
\hline 26 & 3 & 1 & 3 & 1 & 8 \\
\hline 27 & 5 & 5 & 7 & 0 & 17 \\
\hline 28 & 5 & 3 & 10 & 0 & 18 \\
\hline 29 & 2 & 1 & 3 & 0 & 6 \\
\hline 30 & 18 & 3 & 19 & 0 & 40 \\
\hline 31 & 17 & 2 & 13 & 3 & 35 \\
\hline 32 & 4 & 0 & 2 & 1 & 7 \\
\hline 33 & 1 & 0 & 0 & 0 & 1 \\
\hline 34 & 1 & 0 & 0 & 0 & 1 \\
\hline 35 & 6 & 0 & 4 & 0 & 10 \\
\hline 36 & 2 & 0 & 0 & 0 & 2 \\
\hline 37 & 2 & 0 & 0 & 0 & 2 \\
\hline 38 & 1 & 1 & 1 & 0 & 3 \\
\hline 39 & 3 & 1 & 1 & 0 & 5 \\
\hline 40 & 3 & 0 & 1 & 0 & 4 \\
\hline Всего & 215 & 77 & 198 & 14 & 504 \\
\hline
\end{tabular}

Таблица 3. Возрастное распределение ответов респондентов на вопрос «Используете ли Вы для развлечения в свободное времяпровождение сайты сети интернет?»

Table 3. Age distribution of respondents' answers to the question «Do you use Internet sites for entertainment in your free time?»

\begin{tabular}{|c|c|c|c|}
\hline Возраст респондентов & Да & Нет & Всего \\
\hline 1 & 2 & 3 & 4 \\
\hline 17 & 8 & 1 & 9 \\
\hline 18 & 31 & 35 & 66 \\
\hline 19 & 44 & 21 & 65 \\
\hline
\end{tabular}


Продолжение табл. 3

Continued Table 3

\begin{tabular}{|c|c|c|c|}
\hline 1 & 2 & 3 & 4 \\
\hline 20 & 55 & 38 & 93 \\
\hline 21 & 16 & 12 & 28 \\
\hline 22 & 13 & 2 & 15 \\
\hline 23 & 17 & 12 & 29 \\
\hline 24 & 18 & 8 & 26 \\
\hline 25 & 10 & 4 & 14 \\
\hline 26 & 3 & 5 & 8 \\
\hline 27 & 11 & 6 & 17 \\
\hline 28 & 12 & 6 & 18 \\
\hline 29 & 1 & 5 & 6 \\
\hline 30 & 23 & 17 & 40 \\
\hline 31 & 20 & 15 & 35 \\
\hline 32 & 3 & 4 & 7 \\
\hline 33 & 1 & 0 & 1 \\
\hline 34 & 0 & 1 & 1 \\
\hline 35 & 5 & 5 & 10 \\
\hline 36 & 1 & 1 & 2 \\
\hline 37 & 1 & 1 & 2 \\
\hline 38 & 3 & 0 & 3 \\
\hline 39 & 3 & 2 & 5 \\
\hline 40 & 1 & 3 & 4 \\
\hline Всего & 300 & 204 & 504 \\
\hline
\end{tabular}

Таблица 4. Возрастное распределение ответов на вопрос «Используете ли Вы социальную сеть «Вконтакте»?»

Table 4. Age distribution of answers to the question «Do you use the social network Vkontakte?»

\begin{tabular}{|c|c|c|c|}
\hline Возраст респондентов & Да & Нет & Всего \\
\hline 1 & 2 & 3 & 4 \\
\hline 17 & 7 & 2 & 66 \\
\hline 18 & 64 & 2 & 65 \\
\hline 19 & 61 & 4 & 93 \\
\hline 20 & 92 & 1 & 28 \\
\hline 21 & 28 & 0 & 15 \\
\hline 22 & 15 & 0 & 29 \\
\hline 23 & 28 & 1 & 26 \\
\hline 24 & 24 & 2 & 14 \\
\hline 25 & 14 & 0 & 8 \\
\hline 26 & 7 & 1 & \\
\hline
\end{tabular}


Продолжение табл. 4

Continued Table 4

\begin{tabular}{|c|c|c|c|}
\hline 1 & 2 & 3 & 4 \\
\hline 27 & 13 & 4 & 17 \\
\hline 28 & 15 & 3 & 6 \\
\hline 29 & 6 & 0 & 40 \\
\hline 30 & 38 & 3 & 35 \\
\hline 31 & 32 & 0 & 7 \\
\hline 32 & 7 & 0 & 1 \\
\hline 33 & 1 & 1 & 10 \\
\hline 34 & 0 & 2 & 2 \\
\hline 35 & 8 & 0 & 2 \\
\hline 36 & 2 & 1 & 3 \\
\hline 37 & 1 & 0 & 5 \\
\hline 38 & 3 & 0 & 4 \\
\hline 39 & 5 & 0 & 504 \\
\hline 40 & 4 & 29 & 1 \\
\hline Всего & 475 & & \\
\hline
\end{tabular}

Таблица 5. Возрастное распределение ответов на вопрос «Используете ли Вы социальную сеть Facebook?»

Table 5. Age distribution of answers to the question «Do you use the social network Facebook?»

\begin{tabular}{|c|c|c|c|}
\hline Возраст респондентов & Да & Нет & Всего \\
\hline 1 & 2 & 3 & 4 \\
\hline 17 & 0 & 9 & 9 \\
\hline 18 & 1 & 65 & 66 \\
\hline 19 & 2 & 63 & 65 \\
\hline 20 & 0 & 93 & 93 \\
\hline 21 & 1 & 27 & 28 \\
\hline 22 & 3 & 12 & 15 \\
\hline 23 & 4 & 25 & 29 \\
\hline 24 & 2 & 24 & 26 \\
\hline 25 & 2 & 12 & 14 \\
\hline 26 & 1 & 7 & 8 \\
\hline 27 & 2 & 15 & 17 \\
\hline 28 & 4 & 14 & 18 \\
\hline 29 & 0 & 6 & 6 \\
\hline 30 & 1 & 39 & 40 \\
\hline 31 & 1 & 34 & 35 \\
\hline 32 & 2 & 5 & 7 \\
\hline 33 & 0 & 1 & 1 \\
\hline 34 & 0 & 1 & 1 \\
\hline
\end{tabular}


Продолжение табл. 5

Continued Table 5

\begin{tabular}{|c|c|c|c|}
\hline 1 & 2 & 3 & 4 \\
\hline 35 & 2 & 8 & 10 \\
\hline 36 & 0 & 2 & 2 \\
\hline 37 & 0 & 2 & 3 \\
\hline 38 & 0 & 3 & 5 \\
\hline 39 & 1 & 4 & 4 \\
\hline 40 & 2 & 2 & 504 \\
\hline Всего & 31 & 473 & \\
\hline
\end{tabular}

Таблица 6. Возрастное распределение ответов на вопрос

«В свободное время Вы чаще всего посещаете торгово-развлекательные центры?»

Table 6. Age distribution of answers to the question

«Do you most often visit shopping and entertainment centers in your free time?»

\begin{tabular}{|c|c|c|c|}
\hline Возраст респондентов & Да & Нет & Всего \\
\hline 17 & 7 & 2 & 9 \\
\hline 18 & 54 & 12 & 66 \\
\hline 19 & 46 & 19 & 65 \\
\hline 20 & 81 & 12 & 93 \\
\hline 21 & 26 & 2 & 28 \\
\hline 22 & 15 & 0 & 15 \\
\hline 23 & 19 & 10 & 29 \\
\hline 24 & 18 & 8 & 26 \\
\hline 25 & 10 & 4 & 14 \\
\hline 26 & 6 & 2 & 8 \\
\hline 27 & 15 & 2 & 17 \\
\hline 28 & 13 & 5 & 18 \\
\hline 29 & 4 & 2 & 6 \\
\hline 30 & 32 & 8 & 40 \\
\hline 31 & 25 & 10 & 35 \\
\hline 32 & 5 & 2 & 7 \\
\hline 33 & 1 & 0 & 1 \\
\hline 34 & 1 & 0 & 1 \\
\hline 35 & 5 & 5 & 10 \\
\hline 36 & 1 & 1 & 2 \\
\hline 37 & 2 & 0 & 2 \\
\hline 38 & 3 & 0 & 3 \\
\hline 39 & 4 & 1 & 5 \\
\hline 40 & 3 & 1 & 4 \\
\hline Всего & 396 & 108 & 504 \\
\hline
\end{tabular}


Таблица 7. Возрастное распределение ответов на вопрос «В свободное время Вы чаще всего посещаете библиотеку?»

Table 7. Age distribution of answers to the question

«Do you most often visit the library in your free time?»

\begin{tabular}{|c|c|c|c|}
\hline Возраст респондентов & Да & Нет & Всего \\
\hline 17 & 1 & 8 & 9 \\
\hline 18 & 12 & 54 & 66 \\
\hline 19 & 12 & 53 & 65 \\
\hline 20 & 9 & 84 & 93 \\
\hline 21 & 4 & 24 & 28 \\
\hline 22 & 3 & 12 & 15 \\
\hline 23 & 8 & 21 & 29 \\
\hline 24 & 6 & 20 & 26 \\
\hline 25 & 2 & 12 & 14 \\
\hline 26 & 3 & 5 & 8 \\
\hline 27 & 3 & 14 & 17 \\
\hline 28 & 3 & 15 & 18 \\
\hline 29 & 0 & 6 & 6 \\
\hline 30 & 6 & 34 & 40 \\
\hline 31 & 7 & 28 & 35 \\
\hline 32 & 1 & 6 & 7 \\
\hline 33 & 0 & 1 & 1 \\
\hline 34 & 0 & 1 & 1 \\
\hline 35 & 1 & 9 & 10 \\
\hline 36 & 0 & 2 & 2 \\
\hline 37 & 1 & 1 & 2 \\
\hline 38 & 0 & 3 & 3 \\
\hline 39 & 0 & 5 & 5 \\
\hline 40 & 1 & 3 & 4 \\
\hline Всего & 83 & 421 & 504 \\
\hline
\end{tabular}

Ответы респондентов дают понять, что моллы, торгово-развлекательные центры являются преимущественным местом для их свободного времяпровождения. 78,6 \% респондентов отвечают на вопрос положительно. В возрастной категории от 17 до 24 лет эта доля возрастает до 80,4\%.

В табл. 7 представлены ответы респондентов на вопрос, посещают ли они в свободное время библиотеку.

Лишь 16,5 \% респондентов дают положительный ответ на вопрос о посещении библиотеки в свободное время. В воз- растной категории от 17 до 24 лет эта доля незначительно выше - 16,6 \%.

Однако это не означает, что респонденты игнорируют чтение книг. В табл. 8 приведены ответы на вопрос о чтении в свободное время и об источниках книг.

$20 \%$ респондентов или высказали отрицательное отношение к чтению, или не стали отвечать на данный вопрос. В различных форматах - «бумажных», электронных, аудио и других - чтение книг осуществляют около $80 \%$ респондентов. В возрастной категории от 17 до 24 лет 
Таблица 8. Возрастное распределение ответов на вопрос «Любите ли Вы чтение книг?» Table 8. Age distribution of answers to the question «Do you like reading books?»

\begin{tabular}{|c|c|c|c|c|c|c|c|}
\hline $\begin{array}{c}\text { Возраст } \\
\text { респондентов }\end{array}$ & $\begin{array}{c}\text { Очень } \\
\text { люблю, после } \\
\text { прочитанной } \\
\text { книги сразу } \\
\text { берусь для } \\
\text { следующую }\end{array}$ & $\begin{array}{c}\text { Читаю } \\
\text { время } \\
\text { от времени }\end{array}$ & $\begin{array}{c}\text { Считаю, } \\
\text { что можно } \\
\text { активно } \\
\text { слушать } \\
\text { аудиокниги }\end{array}$ & $\begin{array}{c}\text { Читаю } \\
\text { книги, } \\
\text { скачивая их } \\
\text { из интернета }\end{array}$ & $\begin{array}{c}\text { Я не очень } \\
\text { люблю } \\
\text { читать, } \\
\text { читаю редко }\end{array}$ & $\begin{array}{c}\text { Затруд- } \\
\text { няюсь } \\
\text { ответить }\end{array}$ & Всего \\
\hline 17 & 2 & 3 & 1 & 1 & 2 & 0 & 9 \\
\hline 18 & 4 & 47 & 0 & 0 & 10 & 5 & 66 \\
\hline 19 & 10 & 30 & 0 & 4 & 19 & 2 & 65 \\
\hline 20 & 12 & 57 & 0 & 5 & 17 & 2 & 93 \\
\hline 21 & 3 & 13 & 2 & 5 & 3 & 2 & 28 \\
\hline 22 & 2 & 9 & 1 & 2 & 1 & 0 & 15 \\
\hline 23 & 8 & 12 & 0 & 2 & 4 & 3 & 29 \\
\hline 24 & 4 & 16 & 1 & 0 & 5 & 0 & 26 \\
\hline 25 & 4 & 7 & 0 & 0 & 3 & 0 & 14 \\
\hline 26 & 2 & 2 & 0 & 0 & 3 & 1 & 8 \\
\hline 27 & 3 & 7 & 3 & 3 & 1 & 0 & 17 \\
\hline 28 & 5 & 12 & 0 & 0 & 1 & 0 & 18 \\
\hline 29 & 0 & 4 & 0 & 2 & 0 & 0 & 6 \\
\hline 30 & 9 & 19 & 3 & 4 & 4 & 1 & 40 \\
\hline 31 & 5 & 16 & 1 & 5 & 8 & 0 & 35 \\
\hline 32 & 3 & 4 & 0 & 0 & 0 & 0 & 7 \\
\hline 33 & 0 & 0 & 1 & 0 & 0 & 0 & 1 \\
\hline 34 & 0 & 0 & 0 & 0 & 1 & 0 & 1 \\
\hline 35 & 3 & 4 & 1 & 1 & 1 & 0 & 10 \\
\hline 36 & 0 & 2 & 0 & 0 & 0 & 0 & 2 \\
\hline 37 & 1 & 1 & 0 & 0 & 0 & 0 & 2 \\
\hline 38 & 0 & 3 & 0 & 0 & 0 & 0 & 3 \\
\hline 39 & 0 & 2 & 0 & 1 & 2 & 0 & 5 \\
\hline 40 & 0 & 3 & 1 & 0 & 0 & 0 & 4 \\
\hline Всего & 80 & 273 & 15 & 35 & 85 & 16 & 504 \\
\hline
\end{tabular}

$76 \%$ отвечают положительно на вопрос о чтении книг. Но при этом все же чаще всего респонденты всех возрастных категорий выбирают нечетко определенный ответ «читаю время от времени» - 54,1 \% от всех возможных ответов. В возрастной категории от 17 до 24 лет такой ответ выбирают почти $60 \%$ всех респондентов.

Таким образом, ценность социальных коммуникаций оказывается весьма значимой для респондентов, можно назвать ее одной из базовых ценностей для данной социальной категории. К особенностям формирования ценностных представлений студентов российских университетов, расположенных на территории регионов Сибирского федерального округа, можно отнести выбор актуальных символических медиаторов (посредников), в среде которых происходит данный процесс. В настоящее время функции символических медиаторов в большинстве случаев берут на себя со- 
циальные сети (лидирует социальная сеть «Вконтакте») и торгово-развлекательные центры. В свою очередь традиционные символические медиаторы ценностей для студентов - библиотеки - фунцию активной среды для формирования ценностных представлений обучающихся стремительно утрачивают. Одновременно сохраняется и преобладает ценность непосредственного, невиртуального социального взаимодействия. При этом интернет как технологическая основа современных социальных коммуникаций используется в различных аспектах: как пространство социальных сетей, как база и для развлечений, и для чтения книг в аудио- и электронных форматах.

\section{Обсуждение результатов}

Полученные выводы на основе теоретической интерпретации эмпирических данных расширяют понимание современных тенденций и специфику формирования ценностных представлений студентов российских университетов. Можно надеяться, что специалисты в области молодежной политики, которые сегодня начинают активно работать в учреждениях высшего образования, будут использовать различные исследовательские методики для выявления первичного статуса ценностных представлений студентов, и апробированная нами методикас авторским вопросником и обработкой результатов с помощью лицензионного программного обеспечения IBM SPSS также будет включена в этот инструментарий.

Важные данные были получены для тех педагогов, которые разрабатывают современные образовательные технологии достижения универсальной компетенции «многообразие культур» в контексте требований федеральных государственных образовательных стандартов высшего образования. Измерение динамики ценностных представлений студентов по аналогии с результатами данного исследования может быть одним из оценочных средств достижения поставленных образовательных целей.

В настоящее время широко обсуждаются коммуникативные практики со- временных студентов, связанные с использованием социальных сетей. Мы согласны с теми учеными, которые призывают к осторожности и взвешенности введения социальных сетей в образовательный процесс. Так, Ю. Танг и К. Хью предлагают использовать социальную сеть Twitter только для уточнения домашних заданий студентов, данные они справедливо полагают, что необходимы дополнительные исследования эффективности социальных медиа для улучшения образовательных результатов (Tang, Hew, 2017). Полученные нами данные об активном использовании студентами российских университетов социальной сети «Вконтакте» также нуждаются в уточнении и детализации целей этого использования.

Довольно большое количество актуальных исследований связано с возможностями социальной сети Facebook для обучения студентов, в том числе, в электронной игровой форме. Коллектив малазийских и палестинских ученых - С. Могхаввеми и соавторы - полагает, что данные образовательные технологии могут быть внедрены в современных университетах (Tomlinson, 2017). Наши результаты свидетельствуют о том, что российские студенты в возрасте от 17 лет и старше крайне редко используют социальную сеть Facebook, поэтому мы не можем согласиться с данными выводами по отношению к российским университетам, где использование сети Facebook в образовательном процессе будет безрезультативным или неэффективным.

Перевод библиотечных служб университетов на преимущественное предоставление доступа к компьютерным ресурсам, который анализируется в исследовании американских ученых Б. Цвилии и Л. Гибрадзе (Vecchione et al., 2020), - это актуальная тенденция, значимость изменения сути библиотечных сервисов в современных университетах подтверждается полученными нами результатами о том, что посещение библиотеки теряет свою значимость для студентов, а обращение к интернетресурсам в качестве источника для чтения книг, наоборот, возрастает. 
Изменение перечня символических медиаторов, обуславливающих формирование ценностных представлений современных студентов, включение в этот перечень торгово-развлекательных центров обсуждаются, как правило, в маркетинговом контексте. Например, особенности маркетингового поведения студентов в моллах исследует международный коллектив американских, малазийских и австралийских ученых 3. Ахмеда и соавторов. Наши результаты, где высказывается предположение о том, что моллы не только имеют маркетинговое назначение, но и формируют ценностную среду современных студентов, поскольку поход в торгово-развлекательные центры занимает свободное время большого количества студентов, являются достаточно новыми и ранее в исследовательской литературе не обсуждались.

Мы соглашаемся с теми исследователями ценностных представлений российского студенчества, которые фиксируют смещение аксиологического акцента с коллективистических установок на индивидуалистические. Н.В. Буравлева приходит к таким же выводам, ее исследование важно с точки зрения региональной проблематики, так как было сделано с помощью анализа ценностей студенчества Томской области. Одновременно необходимо указать на то, что полученные нами результаты о ценности для студентов непосредственного общения друг с другом не соответствуют результатам российского исследования, выполненного Н.В. Черных, где утверждается, что «согласно результатам исследования, студенты ставят на последнее место общение как ценность, пренебрегая им и не учитывая его необходимость в сфере их будущей профессии». Возможно, что данное несовпадение фиксирует региональную или временную специфику полученных результатов.

В настоящее время в мировой и российской педагогической науке развиваются исследования культурного интеллекта или культурного коэффициента студентов. Мы также фиксируем значимость такой науч- ной работы, и в соответствии с выводами американских ученых М. Веккьоне и соавторов подтверждаем, что теория основных человеческих ценностей обладает большим эвристическим потенциалом.

\section{Заключение}

Исследование особенностей формирования ценностей у студентов современных российских университетов соответствует ключевым тенденциям мировой и отечественной педагогической науки, где фиксируется трансформационный, переходный период ценностных установок студенчества. Трансформации ценностей студентов связаны и с принципиально новой технологической базой образовательного процесса, и с возможностью сравнивать ценности различных социально-демографических групп в связи с большой информированностью современных людей, и с появлением новых социальных особенностей студентов, отличающихся от предшествующих исторических периодов, в том числе недавних.

Необходимо, на наш взгляд, зафиксировать две важные аксиологические тенденции. Во-первых, нельзя переоценивать значимость виртуализации способов социальных коммуникаций для студентов, поскольку ценность непосредственного общения для них выходит сегодня на ключевые позиции. Во-вторых, следует признать важность появления новых символических медиаторов, создающих актуальную ценностную среду в связи с большим объемом времени, которое студенты проводят во взаимодействии с этими символическими медиаторами. Библиотеки, музеи, художественные галлереи, концертные залы теряют свое качество символических медиаторов, а компьютерные сервисы, торговоразвлекательные центры и конкретные социальные сети наращивают данное качество. Следовательно, молодежная политика в университетах должна не только фиксировать данные трансформации, но и учитывать их при планировании своих программных мероприятий. 


\section{References}

Balakrishnan, B., Tochinai, F., Kanemitsu, H., Altalbe, A. (2021). Engineering ethics education from the cultural and religious perspectives: a study among Malaysian undergraduates. In European Journal of Engineering Education, 1-11.

Broadbent, J. (2017). Comparing online and blended learner's self-regulated learning strategies and academic performance. In The Internet and Higher Education, 33, 24-32.

Covarrubias, R. (2021). What We Bring With Us: Investing in Latinx Students Means Investing in Families. In Policy Insights from the Behavioral and Brain Sciences, 8 (1), 3-10.

Deci, E.L., Vallerand, R.J., Pelletier, L.G., Ryan, R.M. (1991). Motivation and education: The selfdetermination perspective. In Educational Psychologist, 3-4 (26), 325-346.

Donald, W.E., Baruch, Y., Ashleigh, M. (2019). The undergraduate self-perception of employability: Human capital, careers advice, and career ownership. In Studies in Higher Education, 44 (4), 599-614.

Earley, P.C., Ang, S. (2003). Cultural intelligence: Individual interactions across cultures. Stanford: Calif: Stanford University Press.

Hu, Y., Dai, K. (2021). Foreign-born Chinese students learning in China: (Re)shaping intercultural identity in higher education institution. In International Journal of Intercultural Relations, 80, 89-98.

$\mathrm{Hu}, \mathrm{S}$., Gu, J., Liu, H., Huang, Q. (2017). The moderating role of social media usage in the relationship among multicultural experiences, cultural intelligence, and individual creativity. In Information Technology People, 30 (2), 265-281.

Katz-Gerro, T. Greenspan, I., Handy, F., Lee, H.Y. (2017). The relationship between value types and environmental behaviour in four countries: Universalism, benevolence, conformity and biospheric values revisited. In Environmental Values, 26 (2), 223-249.

Koptseva, N.P., Kirko, V.I. (2014a). Modern specificity of legal regulation of cultural development of the indigenous peoples of the Arctic Siberia (the Altay Region, the Zabaikailsky Region, Republic of Buryatia, Russia). In Life Science Journal, 11 (9), 314-319.

Koptseva, N.P., Kirko, V.I. (2014b) Specificity of ethnogeny indigenous peoples by central Siberia in the transition from the traditional type of society to modern society. In Life Science Journal, 11 (7), 409-413.

Koptseva, N.P., Reznikova, K.V. (2015). Refinement of the causes of ethnic migration North Selkups based on the historical memory of indigenous ethnic groups Turukhansk district of Krasnoyarsk Krai, In Bylye Gody, 38 (4), 1028-1038.

Louis, K.S., Murphy, J. (2017). Trust, caring and organizational learning: The leader's role. In Journal of educational administration, 55 (1), 103-126.

Makransky, G., Terkildsen, T.S., Mayer, R.E. (2019). Adding immersive virtual reality to a science lab simulation causes more presence but less learning. In Learning and Instruction, 60, 225-236.

Matthews, K.E. Dwyer, A., Hine, L., Turner, J. (2018). Conceptions of students as partners. In Higher Education, 76 (6), 957-971.

Moghavvemi, S., Paramanathan, T., Rahin, N.M., Sharabati, M. (2017). Student's perceptions towards using e-learning via Facebook. In Behaviour \& Information Technology, 36 (10), 1081-1100.

Person, D. R. Kaveh, H., García, Y., Carsey, T.A. (2021). What Leaders Believe: Increasing Educational Attainment Among Urban Youth. In Urban Education, 56 (3), 355-369.

Parong, J., Mayer, R.E. (2018). Learning Science in Immersive Virtual Reality. In Journal of Educational Psychology, 110 (6), 785-797.

Pintrich, P.R., De Groot, E.V. (1990). Motivational and self-regulated learning components of classroom academic performance. In Journal of educational psychology, 82 (1), 33-40.

Ryan, R.M., Deci, E.L. (2000). Self-determination theory and the facilitation of intrinsic motivation, social development, and well-being. In American psychologist, 55(1), 68-78.

Schwartz, S.H., Bilsky W. (1990). K teorii universal'nogo soderzhaniya i struktury cennostej: rasshireniya i kross-kul'turnye replikacii [Toward a theory of the universal content and structure of values: Exten-

$$
-916-
$$


sions and cross-cultural replications]. In Zhurnal lichnosti i social'noj psihologii [Journal of Personality and Social Psychology], 58, 878-891.

Schwartz, S.H. (1992). Universals in the content and structure of values: Theoretical advances and empirical tests in 20 countries. In Advances in experimental social psychology, 25, 1-65.

Schwartz, S.H. Melech, G., Lehmann, A., Burgess, S., Harris, M., Owens, V. (2001). Extending the cross-cultural validity of the theory of basic human values with a different method of measurement. In Journal of cross-cultural psychology, 32 (5), 519-542.

Sortheix, F. M. Parker, P.D., Lechner, C.M., Schwartz, S.H. (2019). Changes in young Europeans' values during the global financial crisis. In Social Psychological and Personality Science, 10 (1), 15-25.

Stvilia, B., Gibradze, L. (2017). Examining undergraduate students' priorities for academic library services and social media communication. In The Journal of Academic Librarianship, 43 (3), 257-262.

Tarhini, A., Hone, K., Liu, X., Tarhini, T. (2017). Examining the moderating effect of individual-level cultural values on users' acceptance of E-learning in developing countries: a structural equation modeling of an extended technology acceptance model. In Interactive Learning Environments, 25 (3), 306-328.

Tang, Y., Hew, K.F. (2017). Using Twitter for education: Beneficial or simply a waste of time? In Computers \& education, 106, 97-118.

Tomlinson, M. (2017). Forms of graduate capital and their relationship to graduate employability. In Education+Training, 59 (4), 338-352.

Vecchione, M., Schwartz, S.H., Davidov, E., Cieciuch, J., Alessandri, G., Marsicano, G. (2020). Stability and change of basic personal values in early adolescence: A 2-year longitudinal study. In Journal of personality, 88 (3), 447-463. 